Indexed by

\title{
SELECTION OF THE PREFERRED DESIGN FOR MANUFACTURABILITY BY CONSTRUCTING THE PARETO TUPLE
}

Crossref

KOBSON

\section{Gamid Irzaev}

Daghestan State Technical

University,

Department of Computer

Technology,

$\mathrm{ROAD}=\quad$ Computer Engineering and

Energy,

Makhachkala,

Russian Federation
Magomedimin Kanaev

Daghestan State Technical

University,

Department of Computer Technology,

Computer Engineering and

Energy,

Makhachkala,

Russian Federation
Marzhanat Isalova

Daghestan State Technical University,

Department of Information Systems, Finance and Audit, Makhachkala,

Russian Federation

Key words: system for ensuring manufacturability, design optimization, quantitative criterion, comparison matrix, Pareto tuple

\section{Cite article:}

Gamid, T., Magomedimin, K., \& Marzhanat I. [2021]. Selection of the preferred design for manufacturability by constructing the pareto tuple. Journal of Applied Engineering Science, 19(2), 275 - 281. DOI:10.5937/jaes0-26922

Online aceess of full paper is available at: www.engineeringscience.rs/browse-issues 


\title{
SELECTION OF THE PREFERRED DESIGN FOR MANUFACTURABILITY BY CONSTRUCTING THE PARETO TUPLE
}

\author{
Gamid Irzaev ${ }^{1 *}$, Magomedimin Kanaev', Marzhanat Isalova ${ }^{2}$ \\ ${ }^{1}$ Daghestan State Technical University, Department of Computer Technology, Computer Engineering and \\ Energy, Makhachkala, Russian Federation \\ ${ }^{2}$ Daghestan State Technical University, Department of Information Systems, Finance and Audit, \\ Makhachkala, Russian Federation
}

The system to ensure manufacturability of industrial products is aimed at reducing the costs of all types of resources at the stages of their life cycle, selecting the most competitive in cost and functionality designs at the early stages of engineering. When assessing the new designs for manufacturability to be developed and selecting the best analogue or basic reference standard in terms of manufacturability, the engineer faces the need to apply multicriteria optimization methods. The solution of the applied task of design optimization by quantitative criteria of manufacturability in the conditions of an uncertain design and production environment is considered in the article as implementable in the system for ensuring design for manufacturability. The decisive rules for implementing the multi-step process of ranking the design options according to the manufacturability criteria with the construction of the Pareto tuple are formed. The implementation of the method is exemplified in practice when choosing the oscilloscope design that is advantageous in terms of manufacturability at a mass-production instrument-making plant

Key words: system for ensuring manufacturability, design optimization, quantitative criterion, comparison matrix, Pareto tuple

\section{INTRODUCTION}

Manufacturability is an essential characteristic of the resource intensity and perfection of products, since it considerably determines the level of technical and economic production factors. In the system for ensuring manufacturability of industrial products, great attention is paid to engineering analysis and optimization of design solutions. These problems were investigated by Anderson, Selvaraj, Barnawal, Gupta et al. [1-4]. The problem of comparative appraisal of technical design options to select the most optimal one among them refers to the class of multicriteria problems and is implemented in the design and production environments in conditions of uncertainty, incomplete information and lack of time.

The system for ensuring manufacturability of products is aimed at providing their design with such a complex of properties, at which the optimal costs of all types of resources are attained at the life cycle stages for given quality indicators, output volume and conditions for work performance. To achieve this aim, the system for ensuring manufacturability, the structure of which is shown in Figure 1, should provide for the solution of the following interrelated issues:

- planning programs to ensure manufacturability of products and bringing them to a specified level;

- accounting for the achieved level of manufacturability with the help of a system of indicators established in the form of regulations and specifications for a given sector;
- controlling design for manufacturability by means of product quantity and quality assessment and introducing engineering changes in the design documents; these questions were described by Hamrazetal.in [5];

- controlling the progress of implementation program to ensure the manufacturability of the product and providing early identification of non-technological designs prior to the start of the production cycle.

During implementation and functioning of the system for ensuring manufacturability of products, a number of scientific, methodological and practical challenges arise at the industrial enterprises [6]. The data accumulated over the periods of monitoring analogous products of a certain class and generalized to form managerial actions affecting designs are extremely heterogeneous and often contradictory. To control product manufacturability properties, both quantitative and qualitative assessments are used, which complicates obtaining an integral control result. The system has weak structuredness, characterized by the incompleteness and uncertainty of the information model through unreliability and insufficiency of information flows about the manufacturability of products. This is revealed by the researchers of Zhou, Cochrane, Young et al. [7-9].

The conducted measurements of engineering and running characteristics and calculations of manufacturability indicators carry a cumulative effect in the engineering and production systems of several processes, often at different stages of development [10,11]. The monitored 
and managed items undergo significant changes in the course of their life cycle (changes in the element base, technological modes, operating conditions), and the system for ensuring manufacturability is unable to fully reflect the objective picture of the product adaptability to efficient manufacturing.

The conducted measurements of engineering and running characteristics and calculations of manufacturability indicators carry a cumulative effect in the engineering and production systems of several processes, often at different stages of development $[10,11]$. The monitored and managed items undergo significant changes in the course of their life cycle (changes in the element base, technological modes, operating conditions), and the system for ensuring manufacturability is unable to fully reflect the objective picture of the product adaptability to efficient manufacturing.
The organizational structure of the system for ensuring manufacturability should have a multilevel arrangement, whose sophistication depends on the scale of the enterprise, product yield, the quantity of items put into production per year, the complexity and novelty of designs and technologies, and the level of technical requirements for the created equipment. It is required to establish efficient management of engineering and production works aimed at creating and mastering new products with low operating costs and high manufacturability, improving the designs of manufactured products by introducing engineering changes that increase their technical level, manufacturability and quality, developing new resource-saving and high-performance production processes and new materials. These topical issues are discussed in the works of Lynn, Sharma et al. [12-14].

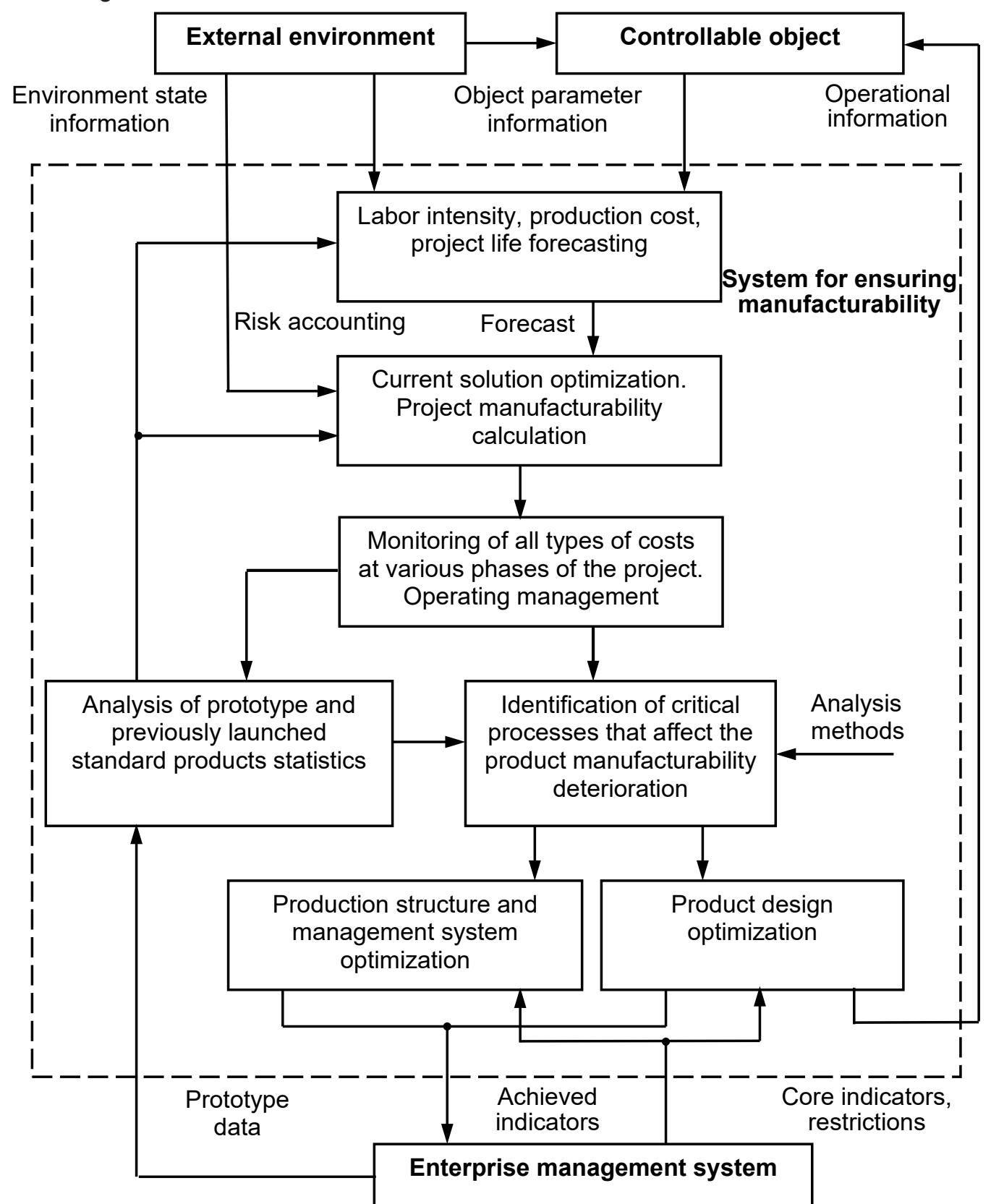

Figure 1: The structure of the system for ensuring product manufacturability in the generalized management cycle 
A system for ensuring manufacturability should be harmoniously introduced into the structure of the enterprise management system and closely interact with it through the flows of planned, operational and directive information.

While creating a system to ensure product manufacturability, comprehensiveness involves multicriteria optimization of the system in the presence of heterogeneous initial data on a dynamic object, identification of its holistic image in terms of manufacturability rather than just determination of a large number of various manufacturability indicators using a variety of methods.

The fuzziness or vagueness of the data characterizing design for manufacturability is the main source of uncertainty in many processes of product optimization with regard to this property. When solving the problems to ensure product manufacturability, the necessity often arises to apply multicriteria optimization methods, for example, when choosing the design option which is most preferable in terms of manufacturability, singling out an analog from a variety of alternatives to be used as a reference standard $[15,16]$. When assessing the manufacturability of newly engineered designs, the correct selection of an analog or a reference standard can significantly affect the level of costs of all types of resources and the further product competitiveness in the market. Examples are given by Trobe-Bateman in [17].

\section{Problem formulation and methodology}

It seems clear that the product, which is optimal from the viewpoint of design for manufacturability, should be sought in the set of its technological solutions. However, due to a large number of such solutions, it would be desirable to have information about the top-down prioritization of high-technology designs. This is established with the help of decisive rules for the selection of design alternatives.

Let us assume that a set of possible design alternative $S=\left\{S_{\alpha}, \alpha=1, n\right\}$ are considered where $n$ is the number of options implementing designs that are assessed for manufacturability by quantitative criteria. The analytical expressions are known for calculation of the partial quantitative criteria of manufacturability $K_{j}\left(S_{\alpha}\right), j=1, r$, where $r$ is the number of particular criteria of designs for manufacturability, and vector criteria $K\left(S_{\alpha}\right)=\left\{K_{1}\left(S_{\alpha}\right), K\right.$ $\left.{ }_{2}\left(S_{\alpha}\right), \ldots, K_{r}\left(S_{\alpha}\right)\right\}$ and $K(S)=\left\{K\left(S_{1}\right), K\left(S_{2}\right), \ldots, K\left(S_{n}\right)\right\}$ characterizing individual alternatives and the entire set of designs, respectively. The set of criteria weight coefficients $B=\left\{b_{i}, j=\overline{1, r\}}\right.$ are also known, where $b_{i}$ is the weight coefficient of the $j$-criterion, assuming that

$$
\sum_{j=1}^{r} b_{j}=1
$$

a set of restriction constant values $D_{0}=\left\{D_{1}{ }^{0}, D_{2}{ }^{0}, \ldots, D_{m}{ }^{0}\right\}$ and a set of restrictions caused by the design features $D\left(S_{\alpha}\right)=\left\{D_{1}\left(S_{\alpha}\right), D_{2}\left(S_{\alpha}\right), \ldots, D_{m}\left(S_{\alpha}\right)\right\}$. During the synthesis of complex designs fulfillment of the following condition is required
$D_{y}\left(S_{a}\right) \leq D_{y}^{0}, y=\overline{1, m}$

A subset of effective ordered designs (Pareto tuple) $P_{R}$ should be found, with the following expression holding for individual elements of this subset

$K\left(S_{p}^{0}\right)=\min _{S_{\alpha} \in S} K\left(S_{\alpha}\right), S_{p}^{0} \in P_{R}$

if the condition (1) is fulfilled.

Assume the above described $S, K\left(S_{\alpha}\right)$, B sets are known. The formation of a set of the criteria weight coefficients $B=\left\{b_{j} j=\overline{1, r}\right\}$ for is given, for example, in [18] and is not considered here. It is required to select the technologically feasible designs for manufacturability, i.e. to construct a Pareto tuple.

To solve the problem, first let us construct a comparison matrix $\left\|C_{k l}\right\|(k=\overline{1, n ;} l=\overline{1, n ; k \neq l})$, where we will enter the assessments obtained on the basis of pairwise comparison of designs $S_{k}, S_{1}(k=\overline{1, n ;} I=\overline{1, n ; k \neq 1})$

unambiguously determining the correlation between the $k$-th and the $l$-th designs. The values of the $C_{k l}$ elements of the comparison matrix will be tried so as to cut off technologically unfeasible design options.

The equivalent systems $S_{k}, S$, have all the relevant quantitative criteria being equal, therefore $C_{k l}=C_{i k}=1$. The designs with all the $k$-th design criteria values worse than those of the l-th design $\left(C_{k l}=N_{2}>>1\right)$, or the values of the $m(m<r)$ criteria of the $k$-th design are worse than the relevant values of the $l$-th design criteria with equal respective values of the remaining quantitative criteria of these designs $\left(C_{k l}=N_{3}, 1<<N_{3}<N_{2}\right)$ will be referred to the technologically unfeasible ones.

Let us denote the subsets of indices of the best, worst, and equal criteria as $Q_{k p}^{+}, Q_{k \mid}^{-}, Q_{k l}^{=}$, respectively, for each pair of design options $S_{k}, S_{1}(k=\overline{1, n ;} l=\overline{1, n ; k \neq l)}$. Then correspondence to the values of the subsets of indices of the best, worst and equal quantitative criteria to the element values in the comparison matrix will be as follows:

if $Q_{k l}^{+}=\varnothing, Q_{k l}^{-}=\varnothing, Q_{k l}^{=}=\{\overline{1, r}\}$, then $C_{k l}=1, C_{l k}=1$

if $Q_{k l}^{+}=\{1, r\}, Q_{k l}^{-}=\varnothing, Q_{k l}^{=}=\varnothing$, then $C_{k l}=N_{2}, C_{l k}=0, N_{2}>>1$

if $Q_{k l}^{+}=\varnothing, Q_{k l}^{-}=\{\overline{1, r}\}, Q_{k l}^{=}=\varnothing$, then $C_{k l}=0, C_{l k}=N_{2}$

if $Q_{k l}^{+} \neq \varnothing, Q_{k l}^{-}=\varnothing, Q_{k l}^{=} \neq \varnothing$, then $C_{k l}=N_{3}, C_{l k}=0,1<<N_{3}<N_{2}$

if $Q_{k l}^{+}=\varnothing, Q_{k l}^{-} \neq \varnothing, Q_{k l}^{=} \neq \varnothing$, then $C_{k l}=0, C_{l k}=N_{3}$

if $Q_{k l}^{+} \neq \varnothing, Q_{k l}^{-} \neq \varnothing,\left|Q_{k l}^{=}\right| \geq \varnothing$ then according to Roy [19] let us determine

$$
C_{k l}=\sum_{j \in Q_{k l}^{+}} b_{j}\left(\sum_{j \in Q_{k l}^{-}} b_{j}\right)^{-1}, C_{l k}=C_{k l}^{-1}
$$

If in the $/$-th $(l \epsilon\{\overline{1, n}\})$ column of the comparison matrix the maximum element is greater than or equal to the value of $N_{2}$, then the l-th design option does not belong to the set of effective solutions by the criterion of manufacturability, and it should be removed from further consideration.

Next, let us introduce characteristics showing the number of elements in the l-th column of the comparison matrix, whose values are greater than unity $-H_{j}$; the number of elements in the $I$-th column of the comparison matrix, 
whose value is less than unity $-M_{j}$; the maximum value in the l-th column of the comparison matrix $-C_{k l m a x} . H_{\text {I }}$ shows the amount of designs from the entire set under consideration which exceed some l-th construction in terms of manufacturability. The $M_{1}$ characteristic shows the amount of design options that are dominated by the I-th option in terms of manufacturability. The $C_{k \text { max }}$ characteristic determines how many times the $k$-th design prevails over (dominates) the $l$-th design with regard to manufacturability.

The method of optimization of design for manufacturability using quantitative criteria is implemented as a multistep process and it is shown in a generalized form as an algorithm in Figure 2.

At each step $t(t=1,2, \ldots, n-1)$ the $H_{l}^{(t)}, M_{l}^{(t)}, C_{k l}{ }^{(t)}$ max characteristics are found for the comparison matrix $\left\|C_{k l}\right\|$, constructed taking into account conditions (2)(7), the best design $S_{j}$ with the minimum value of $H_{l}^{(t)}$ and $C_{l j} \geq 1 \forall I \in\{1, n\}, \mid \neq j$ is determined. The number of the best design for manufacturability identified at this step is included in the Pareto tuple $P$. Next, the $j$-th row and $j$-th column are deleted from the comparison matrix $\left\|C_{k l}\right\|$ to exclude the impact of the $S_{j}$ design on the selection of the best system at the next step $(t+1)$.

If the designs with numbers $I_{i} \in L_{k}(t)=\left\{I_{1}, I_{2}, \ldots, I_{j}, \ldots I_{k}(t)\right\}$ have similar minimum values $H_{l_{j}}^{(t)}$, then the $S_{l j}$ design with the maximum value $M_{l_{j}}^{(t)}=\max _{l_{l_{j}}}$ is the best one. If the designs with numbers $I_{j} \in L_{k}(t)=\left\{I_{1}, I_{2}, \ldots, I_{j}, \ldots, I_{k}(t)\right\}$ have similar values $H_{l j}^{(t)}, M_{l j}^{(t)}$, respectively, then it is necessary to single out the submatrix with the column and row numbers from the comparison matrix and perform rank correlation of its elements.

Equivalent designs should be ordered based on the analysis of the $H_{l}^{(1)}, M_{l}^{(1)}, C_{k l \max }^{(1)}$ characteristics obtained at the first step.

\section{RESULTS}

At the instrument-making enterprise It was required to select an oscilloscope design option that would be most optimal from the viewpoint of manufacturability from a number of alternative designs of the same class, which had been put into mass production by the company previously. The values of the quantitative criteria of manufacturability for five oscilloscopes are given in Table 1.

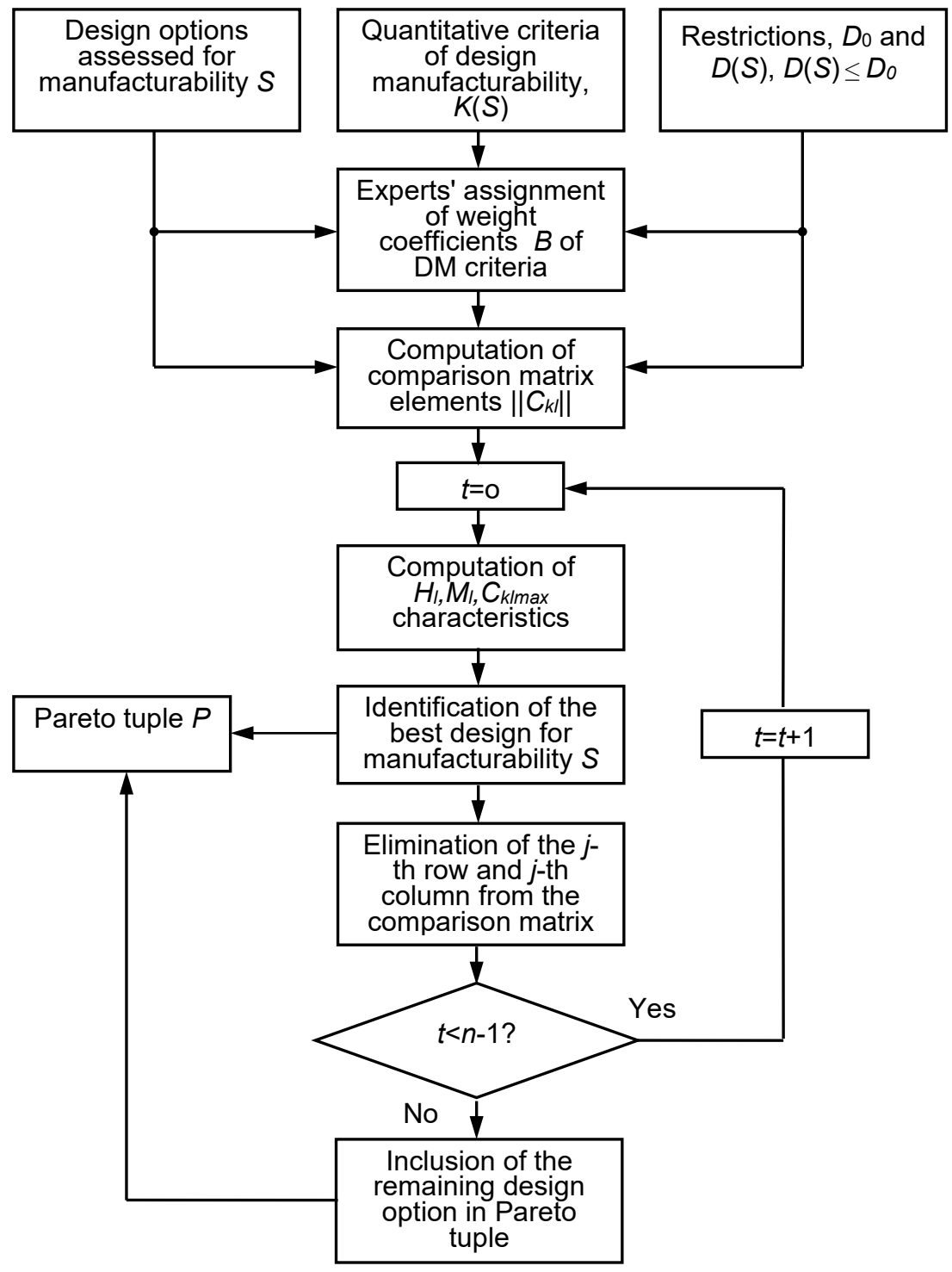

Figure 2: Algorithm for optimization of product designs for manufacturability using quantitative criteria 
Table 1: Quantitative criteria of manufacturability

\begin{tabular}{|c|c|c|c|c|c|}
\hline Manufacturability criteria & \multicolumn{5}{|c|}{ Oscilloscope types } \\
\cline { 2 - 6 } & $\mathrm{C} 1-120$ & $\mathrm{C} 1-122 / 1$ & $\mathrm{C} 1-125$ & $\mathrm{C} 1-126$ & $\mathrm{C} 1-127$ \\
\hline Production cost $K_{1}\left(S_{\alpha}\right)$, RUB thous. & 6.11 & 5.78 & 7.34 & 7.65 & 9.23 \\
\hline Design labor intensity $K_{2}\left(S_{\alpha}\right)$, standard hour & 867 & 769 & 924 & 967 & 1028 \\
\hline $\begin{array}{c}\text { Number of microcircuits and microassembly modules } K_{3}\left(S_{\alpha}\right), \\
\text { pcs. }\end{array}$ & 7 & 12 & 11 & 13 & 11 \\
\hline Repeatability factor for component parts $K_{4}\left(S_{\alpha}\right)$ & 0.56 & 0.58 & 0.34 & 0.65 & 0.67 \\
\hline
\end{tabular}

Table 2: Criteria weight coefficients assigned by the experts

\begin{tabular}{|c|c|}
\hline Criteria $K_{i}\left(S_{\sigma}\right)$ & Weight coefficients, $b_{i}$ \\
\hline$K_{1}\left(S_{\alpha}\right)$ & $b_{1}=0.5$ \\
\hline$K_{2}\left(S_{\alpha}\right)$ & $b_{2}=0.25$ \\
\hline$K_{3}\left(S_{\alpha}\right)$ & $b_{3}=0.1$ \\
\hline$K_{4}\left(S_{\alpha}\right)$ & $b_{4}=0.15$ \\
\hline
\end{tabular}

Table 3: The first-level comparison matrix

\begin{tabular}{|c|c|c|c|c|c|}
\hline \multirow{2}{*}{$\begin{array}{c}\text { Oscillo- } \\
\text { scope } \\
\text { type }\end{array}$} & \multicolumn{5}{|c|}{ Oscilloscope type } \\
\cline { 2 - 6 } & $\begin{array}{c}\mathrm{C} 1- \\
120\end{array}$ & $\begin{array}{c}\mathrm{C} 1- \\
122 / 1\end{array}$ & $\begin{array}{c}\mathrm{C} 1- \\
125\end{array}$ & $\begin{array}{c}\mathrm{C} 1- \\
126\end{array}$ & $\mathrm{C} 1-127$ \\
\hline $\mathrm{C} 1-120$ & - & 0 & 9 & 3 & 3 \\
\hline $\begin{array}{c}\mathrm{C} 1- \\
122 / 1\end{array}$ & $N_{2}$ & - & $N_{2}$ & 3 & 5.67 \\
\hline $\mathrm{C} 1-125$ & 0.111 & 0 & - & 3 & 5 \\
\hline $\mathrm{C} 1-126$ & 0.333 & 0.333 & 0.333 & - & 5.67 \\
\hline $\mathrm{C} 1-127$ & 0.333 & 0.176 & 0.2 & 0.176 & - \\
\hline
\end{tabular}

The criteria weight coefficients given in Table 2, were assigned by the experts from among the preselected competent designers and technologists of the enterprise having long work experience. The first-level comparison matrix is given in Table 3 .

The values of the comparison matrix elements are calculated in accordance with formulas (2) - (7). The characteristics of the device designs $H_{l}^{(1)}, M_{l}^{(1)}, C_{k l}^{(1)}$ max , obtained at the first step of the analysis, are given in Table 4. It can be seen from Table 4 that in the two columns of the comparison matrix, the maximum element equals to $\mathrm{N}_{2}$. Consequently, the designs of the $\mathrm{C} 1-120$ and $\mathrm{C} 1-125$ oscilloscopes are inefficient in terms of manufacturability, therefore, the first and third columns and rows are deleted from the matrix.

At the next step, the characteristics $H_{l}^{(2)}, M_{l}^{(2)}, C_{k l}^{(2)}{ }_{\max }$ are

Table 4: Characteristics of the device designs obtained at the first step of the analysis

\begin{tabular}{|c|c|c|c|c|c|}
\hline $\begin{array}{c}\text { Char- } \\
\text { acter- } \\
\text { istics }\end{array}$ & \multicolumn{5}{|c|}{ Oscilloscope type } \\
\cline { 2 - 6 } & $\mathrm{C} 1-120$ & $\mathrm{C} 1-122 / 1$ & $\mathrm{C} 1-125$ & $\mathrm{C} 1-126$ & $\mathrm{C} 1-127$ \\
\hline$H_{1}^{(1)}$ & 1 & 0 & 2 & 3 & 4 \\
\hline$M_{l}^{(1)}$ & 3 & 4 & 2 & 1 & 0 \\
\hline$C_{k !}^{(1)} \max$ & $N_{2}$ & 0.333 & $N_{2}$ & 3 & 5.67 \\
\hline
\end{tabular}

Table 5: The second-level comparison matrix

\begin{tabular}{|c|c|c|c|}
\hline \multirow{2}{*}{ Oscilloscope type } & \multicolumn{3}{|c|}{ Oscilloscope type } \\
\cline { 2 - 4 } & $\mathrm{C} 1-122 / 1$ & $\mathrm{C} 1-126$ & $\mathrm{C} 1-127$ \\
\hline $\mathrm{C} 1-122 / 1$ & - & 3 & 5.67 \\
\hline $\mathrm{C} 1-126$ & 0.333 & - & 5.67 \\
\hline $\mathrm{C} 1-127$ & 0.176 & 0.176 & - \\
\hline
\end{tabular}

Table 6: Characteristics of the device designs obtained at the second step of analysis

\begin{tabular}{|c|c|c|c|}
\hline \multirow{2}{*}{ Characteristics } & \multicolumn{3}{|c|}{ Oscilloscope type } \\
\cline { 2 - 4 } & $\mathrm{C} 1-122 / 1$ & $\mathrm{C} 1-126$ & $\mathrm{C} 1-127$ \\
\hline$H_{l}^{(2)}$ & 0 & 1 & 2 \\
\hline$M_{l}^{(2)}$ & 2 & 1 & 0 \\
\hline$C_{k l}^{(2)} \max _{\operatorname{myy}}$ & 0.333 & 3 & 5.67 \\
\hline
\end{tabular}

found for the adjusted comparison matrix of the 2 nd level shown in Table 5 . They are given in Table 6.

The C1-122/1 oscilloscope has been recognized as the best design for manufacturability, since its characteristic $H_{l}^{(2)}$. It will be introduced in the Pareto tuple. Next, at the third step, the third-level comparison matrix is constructed, removing the first row and column from the previous level matrix and the table of characteristics for the remaining device designs. Comparison matrix and values of the characteristics are shown in Tables 7 and 8, respectively.

The C1-126 oscilloscope design turns to be the best in terms of manufacturability at the last step, let us include it in the Pareto tuple. As a result, the Pareto tuple is given by: $P=\langle C 1-122 / 1, C 1-126, C 1-127\rangle$.

Table 7: The third-level comparison matrix

\begin{tabular}{|c|c|c|}
\hline \multirow{2}{*}{ Oscilloscope type } & \multicolumn{2}{|c|}{ Oscilloscope type } \\
\cline { 2 - 3 } & $\mathrm{C} 1-126$ & $\mathrm{C} 1-127$ \\
\hline $\mathrm{C} 1-126$ & - & 5.67 \\
\hline $\mathrm{C} 1-127$ & 0.176 & - \\
\hline
\end{tabular}

Table 8: Characteristics of the device designs obtained at the third step of the analysis

\begin{tabular}{|c|c|c|}
\hline \multirow{2}{*}{ Characteristics } & \multicolumn{2}{|c|}{ Oscilloscope type } \\
\cline { 2 - 3 } & $\mathrm{C} 1-126$ & $\mathrm{C} 1-127$ \\
\hline$H_{l}^{(3)}$ & 0 & 1 \\
\hline$M_{l}^{(3)}$ & 1 & 0 \\
\hline$C_{k l}^{(3)} \max$ & 0.176 & 5.67 \\
\hline
\end{tabular}




\section{CONCLUSIONS}

The applied problem of optimizing the design of complex technical products has been solved by the criteria characterizing manufacturability in the engineering and production conditions. The problem is reduced to the construction of an ordered set of technological design options in the form of the Pareto tuple. The solution has been considered for the case when the criteria are given in a formalized quantitative form. The proposed model has been confirmed by the results of an experiment conducted at a mass production plant for a group of measuring devices.

The method can be applied in the development of designs for manufacturability in the course of engineering and technological preparation of production, when selecting the best alternative technical products in terms of manufacturability and quality. The results of the selection of alternatives can be affected by the subjectivity of expert assessments, which can be minimized by engaging experienced experts in the design review, abiding by the rules of sample representativeness and opinion consistency.

\section{REFERENCES}

1. Anderson, D.M. (2014). Design for Manufacturability: How to use concurrent engineering to rapidly develop low-cost high-quality products for lean production. New York: Productivity Press. DOI: 10.1201/ b16501.

2. Selvaraj, P., Radhakrishnan, P. and Adithan, M. (2009). An integrated approach to design for manufacturing and assembly based on reduction of product development time and cost. The International Journal of Advanced Manufacturing Technology, Vol. 42, No. 1-2, 13-29. DOI: 10.1007/s00170-008-1580-8.

3. Barnawal, P., Dorneich, M.C., Peters, F. and Frank, M.C. (2016). Design and evaluation of designer feedback system in design for manufacturability.Proceedings of the Human Factors and Ergonomics Society Annual Meeting, Vol. 59, No 1, 1142-1146. DOI: 10.1177/1541931215591167.

4. Gupta, S.K., Regli, W.C., Das, D. and Nau, D.S. (1997). Automated manufacturability analysis: a survey. Research in Engineering Design, Vol. 9, No 3, 168-190.

5. Hamraz, B., Caldwell, N.H.M., Ridgman, T.W. and Clarkson, P.J. (2015). A FBS Linkage ontology and technique to support engineering change management.Research in Engineering Design, Vol. 26, No 1, 3-35. DOI: 10.1007/s00163-014-0181-9.

6. Shukor, S.A. and Axinte, D. (2009). Manufacturability analysis system: issues and future trends. International Journal of Production Research, Vol. 47, 1369-1390. DOI: 10.1080/00207540701589398.
7. Zhou, Yu. and Saitou, K. (2014). Identification of manufacturability constraints through process simulation and data mining, 19th Design for Manufacturing and the Life Cycle Conference, Buffalo, New York, USA. DOI: 10.1115/DETC2014-34542.

8. Cochrane, S., Young, R., Case, K., Harding, J., Gao, J., Dani, Sh. and Baxter, D. (2008). Knowledge reuse in manufacturability analysis. Robotics and Computer-Integrated Manufacturing, Vol. 24, No 4, 508-513. DOI:10.1016/j.rcim.2007.07.003.

9. Young, R.I.M, Guerra, D., Gunendran, G., Das, B., Cochrane, S. and Cutting-Decelle, A-F. (2005). Sharing manufacturing information and knowledge in design decision support. In: A. Bramley, D. Brissaud, D. Coutellier and McMahon, C. (Eds.), Advances in integrated design and manufacturing in mechanical engineering (pp. 173-188), Netherlands: Springer.

10. Menold, J., Simpson, T.W. and Jablokow, K. (2018). The prototype for $\mathrm{X}$ framework: exploring the effects of a structured prototyping framework on functional prototypes. Research in Engineering Design, DOI: 10.1007/s00163-018-0289-4.

11. Salhieh,S.M. (2008). Developing manufacturing response models to predict the manufacturability of new modular products. The International Journal of Advanced Manufacturing Technology, Vol. 39, No 5-6, 599-611. DOI:10.1007/s00170-007-1232-4.

12. Irzaev, G.Kh. (2018). Multicriteria analysis of product operational effectiveness at design stages. 1th International Conference on Mechanical Engineering, Automation and Control Systems, MEACS 2017, Tomsk, Russian Federation, IOP Conf. Ser.: Mater. Sci. Eng., Vol. 327, Issue 2, 022-049, DOI: 10.1088/1757-899X/327/2/022049.

13. Lynn, R., Saldana, Ch., Kurfess, T., Reddy, N., Simpson, T., Jablokow, K., Tucker, T., Tedia, S. and Williams, Ch. (2016). Toward rapid manufacturability analysis tools for engineering design education. Procedia Manufacturing, Vol. 5, 1183-1196, DOI: 10.1016/j.promfg.2016.08.093.

14. Sharma, R. and Gao, J.X. (2007). A knowledge-based manufacturing and cost evaluation system for product design/re-design. The International Journal of Advanced Manufacturing Technology, Vol. 33, No 9-10, 856-865.DOI: 10.1007/s00170-0060530-6.

15. Kim, Yu-Gyeong, Jung, Yung-Jin, Kim, Hyun-Soo and Ahn, Hee-Jae. (2015). Design assessment of triangular support bracket for manufacturability. Fusion Engineering and Design, Vol. 98-99, 1519-1523, DOI: 10.1016/j.fusengdes.2015.05.004. 
16. Zhang, Jiang-Long, Zhang, Zheng and Han, Yu. (2017). Research on manufacturability optimization of discrete products with 3D printing involved and lot-size considered. Journal of Manufacturing Systems, Vol. 43, No 1, 150-159, DOI:10.1016/j. jmsy.2017.03.002.

17. Trobe-Bateman, J. La and Wild,D. (2003). Design for manufacturing: use of a spreadsheet model of manufacturability to optimize product design and development. Research in Engineering Design, Vol. 14, No 2, (2003), 107-117.
18. Irzaev, G.Kh. (2007). Expert selection of the preferred option for manufacturability products by analytical hierarchy. Proceedings of Irkutsk State Technical University. Vol. 29, No 1, 126-130.

19. Roy, B. (1968). Classementetchoixen presence de points de vue multiples (la methode ELECTRE). RAIRO - Operations Research - Recherche Operationnelle, Vol. 2, No. V1, 57-75. 